\title{
New insights and antimicrobial stewardship opportunities in viral pneumonia: five lung ultrasound cases
}

\author{
Lukas Antonitsch (D) - Ronald Gallob · Gerhard Weidinger · Joachim Kettenbach
}

Received: 23 January 2021 / Accepted: 25 August 2021 / Published online: 4 October 2021

(C) Springer-Verlag GmbH Austria, part of Springer Nature 2021

\begin{abstract}
Summary
Background Antimicrobial stewardship is crucial to avoid antimicrobial resistance in microbes and adverse drug effects in patients. In respiratory infections, however, viral pneumonia is difficult to distinguish from bacterial pneumonia, which explains the overuse of antibiotic therapy in this indication.

Cases Five cases of lung consolidation are presented. Lung ultrasound, in conjunction with procalcitonin levels, were used to exclude or corroborate bacterial pneumonia.
\end{abstract}

Transparency declarations The article was proofread by a professional proof reader, Mary McAllister, regarding English language.

Availability of data and materials Not applicable-Records of laboratory values and images as given in the text or table are saved on our hospital server. If strongly needed, they could be provided.

Supplementary Information The online version of this article (https://doi.org/10.1007/s00508-021-01946-4) contains supplementary material, which is available to authorized users.

\section{Antonitsch $(\bowtie) \cdot G$. Weidinger}

Department of Internal Medicine and Gastroenterology, Landesklinikum Wiener Neustadt, Corvinusring

3-5, 2700 Wiener Neustadt, Austria

lukas.antonitsch@wienerneustadt.lknoe.at

\section{R. Gallob}

Department of Anesthesia, Emergency Medicine and Intensive Care, Landesklinikum Wiener Neustadt, Corvinusring 3-5, 2700 Wiener Neustadt, Austria

\section{J. Kettenbach}

Institute of Diagnostic, Interventional Radiology and Nuclear Medicine, Landesklinikum Wiener Neustadt, Corvinusring 3-5, 2700 Wiener Neustadt, Austria joachim.kettenbach@wienerneustadt.lknoe.at
Conclusion Lung ultrasound is easy to learn and perform and is helpful in guiding diagnosis in unclear cases of pneumonia and may also offer new insights into the spectrum of certain virus diseases. The use of lung ultrasound can raise awareness in clinicians of the need for antimicrobial stewardship and may help to avoid the unnecessary use of antibiotics.

Keywords Lung ultrasound · Pneumonia · Antimicrobial stewardship · Virus · Positive-strand RNA Viruses (Astroviridae; Norovirus)

\begin{tabular}{|c|c|}
\hline \multicolumn{2}{|c|}{ Abbreviations } \\
\hline ABS & Antimicrobial stewardship \\
\hline COVID 19 & Coronavirus disease 2019 \\
\hline CT & Computed tomography \\
\hline CVID & Common variable immune deficiency \\
\hline LUS & Lung ultrasound \\
\hline PCR & Polymerase chain reaction \\
\hline PCT & Procalcitonin \\
\hline SARS-CoV-2 & $\begin{array}{l}\text { Severe acute respiratory syndrome } \\
\text { coronavirus } 2\end{array}$ \\
\hline
\end{tabular}

\section{Introduction}

Antibiotics should be limited to the treatment of infections caused by bacteria in community-acquired [1-8] and nosocomial infections $[9,10]$, and thus, to lower the risk of bacterial resistance [11-14], e.g., by antimicrobial stewardship (ABS) [15]. In acute respiratory infections, however, it can be difficult to distinguish between bacterial and viral causes [16], which is also relevant in nosocomial infections [17-30]. Antibiotic therapy in the absence of bacterial infection may worsen the outcome in viral infections [31].

Procalcitonin (PCT)-guided therapy may reduce antibiotic consumption while lowering mortality in respiratory infections [32-35]. In viral respiratory infec- 
tions diagnosed by multiplex polymerase chain reaction (PCR), bacterial superinfection can be ruled out by a low PCT level [36, 37]; however, conflicting data and low adherence to PCT-guided therapy has been shown in clinical practice [38] and the detection rate of PCR for virus infection can be low $[16,36]$.

Lung ultrasound (LUS) [39] and computed tomography (CT) are more sensitive than X-ray films for the detection of the signs of pneumonia [16] and have been used to distinguish viral from bacterial pneumonia [40, 41]. LUS is easy to learn [42], widely available, and has shown to be indicative of viral infection [43, 44], as has CT even in the absence of positive PCR [45].

\section{Methods}

To distinguish viral from bacterial infection, the following LUS signs were used: multiple small shred signs $<2 \mathrm{~cm}$ and pleural irregularities were indicative of viral disease, whereas shred signs $>3 \mathrm{~cm}$ and hepatization of lung tissue were indicative of bacterial infection [39-44]. ABS advice, i.e. to stop antibiotic therapy in the absence of bacterial pneumonia, was given as appropriate (see supplementary material).

\section{Results}

\section{Case 1: Infection of lungs and intestines}

A 66-year-old female with a history of hypertension, cholecystectomy, struma nodosa and diverticulosis, presented with fever and dry cough; COVID-19 PCR as well as PCT were negative (Table 1). Ampicillin/ sulbactam was started. Because of left lower abdominal pain and diarrhea, an ultrasound examination revealed intestinal wall thickening and diverticulosis, but no surrounding inflammation or abscess. For nonetheless suspected diverticulitis the therapy was changed to ciprofloxacin.

LUS revealed shred signs below $1 \mathrm{~cm}$ in diameter with focal B-lines in the right upper and left lower lung. Meanwhile, the patient complained of night sweats and diarrhea, but no longer of cough or fever. Therefore, the withdrawal of antibiotics was suggested, but the treating physicians decided to continue ciprofloxacin for a total of 10 days and added metronidazole. Soon thereafter, a positive stool test for astrovirus became available.

\section{Case 1-Discussion}

Gastroenteritis is the most often recognized manifestation of astrovirus infection; however, extraintestinal manifestations include a rare case of respiratory infection [46]. Considering diverticulitis as a differential diagnosis (despite only diverticulosis being evident), antibiotic therapy nonetheless can be avoided in uncomplicated cases, especially with a low PCT level [47]. Albeit the proof of the causative pathogen was available only retrospectively, LUS pointed toward a viral cause of infection and management without antibiotic therapy would have been appropriate.

\section{Case 2: Chronic lung pathology with viral infection}

An 84-year-old male with a history of smoking (70 pack years), surgical resection of bladder cancer, aortic stent graft, and transient ischemic attack was evaluated due to unsteady behavior for 1 week. No relevant neurologic signs were observed, but fever and polyuria were noticed. A chest film revealed rightsided patchy infiltrates. The patient was discharged with oral amoxicillin/clavulanic acid.

About 10 days later, he was admitted due to ongoing cough, fever, and rising CRP levels. Intravenous ampicillin/sulbactam was initiated, while the PCT level remained below $0.25 \mathrm{ng} / \mathrm{ml}$ (Table 1$)$.

Table 1 Relevant laboratory results during the disease course; see text and supplementary material. With procalcitonin, different cut-off values have been given in the literature [32, 33, 35, 36]. In our institution, $0.5 \mathrm{ng} / \mathrm{ml}$ is used, as recommended by our Department of Laboratory Medicine

\begin{tabular}{|c|c|c|c|c|c|c|}
\hline & $\begin{array}{l}\text { Reference val- } \\
\text { ues }\end{array}$ & Case 1 & Case 2 & Case 3 & Case 4 & Case 5 \\
\hline White blood cell count & $3.6-10.5 \mathrm{G} / \mathrm{L}$ & $8.7 \mathrm{G} / \mathrm{L}$ & $8.1 \mathrm{G} / \mathrm{L}$ & $10.5 \mathrm{G} / \mathrm{L}$ & Left shift $(1.4 \%)^{\mathrm{a}}$ & $2.15 \mathrm{G} / \mathrm{L}$ \\
\hline Lymphocytes & $1.1-4 \mathrm{G} / \mathrm{L}$ & $0.6 \mathrm{G} / \mathrm{L}$ & $0.6 \mathrm{G} / \mathrm{L}$ & $0.9 \mathrm{G} / \mathrm{L}$ & $0.38 \mathrm{G} / \mathrm{L}$ & $0.96 \mathrm{G} / \mathrm{L}$ \\
\hline C-reactive Protein & $0-0.5 \mathrm{mg} / \mathrm{dl}$ & $17.4 \mathrm{mg} / \mathrm{dL}$ & $10.1 \mathrm{mg} / \mathrm{dl}$ & $28.5 \mathrm{mg} / \mathrm{dl}$ & $38 \mathrm{mg} / \mathrm{dl}$ & $16.1 \mathrm{mg} / \mathrm{dl}$ \\
\hline Procalcitonin & $0-0.5 \mathrm{ng} / \mathrm{mL}$ & $0.2 \mathrm{ng} / \mathrm{ml}$ & $<0.25 \mathrm{ng} / \mathrm{ml}$ & $0.2 \mathrm{ng} / \mathrm{ml}$ & $31.7 \mathrm{ng} / \mathrm{ml}$ & $0.3 \mathrm{ng} / \mathrm{ml}$ \\
\hline D-dimer & $<0.5 \mu \mathrm{g} / \mathrm{ml}$ & - & $5.0 \mu \mathrm{g} / \mathrm{ml}$ & - & - & - \\
\hline Lactate dehydrogenase & $20-250 \mathrm{U} / \mathrm{L}$ & - & $315 \mathrm{U} / \mathrm{L}$ & - & - & - \\
\hline $\begin{array}{l}\text { Nasopharyngeal swab (multi- } \\
\text { plex PCR) }\end{array}$ & - & Negative & Negative & - & - & - \\
\hline $\begin{array}{l}\text { Nasopharyngeal swab } \\
\text { (COVID-19-PCR) }\end{array}$ & - & Negative & Negative & Negative & Negative & Negative \\
\hline COVID-19 Antibodies & - & - & Negative & $\lg M+\lg G$ & Negative & - \\
\hline Miscellaneous (see text) & - & $\begin{array}{l}\text { Astrovirus-Antigen } \\
\text { (Stool/ELISA) }\end{array}$ & $\begin{array}{l}\text { Pyuria } \\
(500 \text { cells/ } \mu l)\end{array}$ & - & $\begin{array}{l}\text { Pneumococcal urinary antigen } \\
\text { Enterovirus lgM }\end{array}$ & $\begin{array}{l}\text { Norovirus } \\
\text { (Stool/PCR) }\end{array}$ \\
\hline
\end{tabular}


Fig. 1 Case 3: a X-ray film shows bilateral, almost symmetrical subpleural infiltrates; b CT-Scan shows bilateral, almost symmetrical consolidation and some ground-glass infiltrates in the lung periphery in this case of COVID-19 pneumonia a few days later
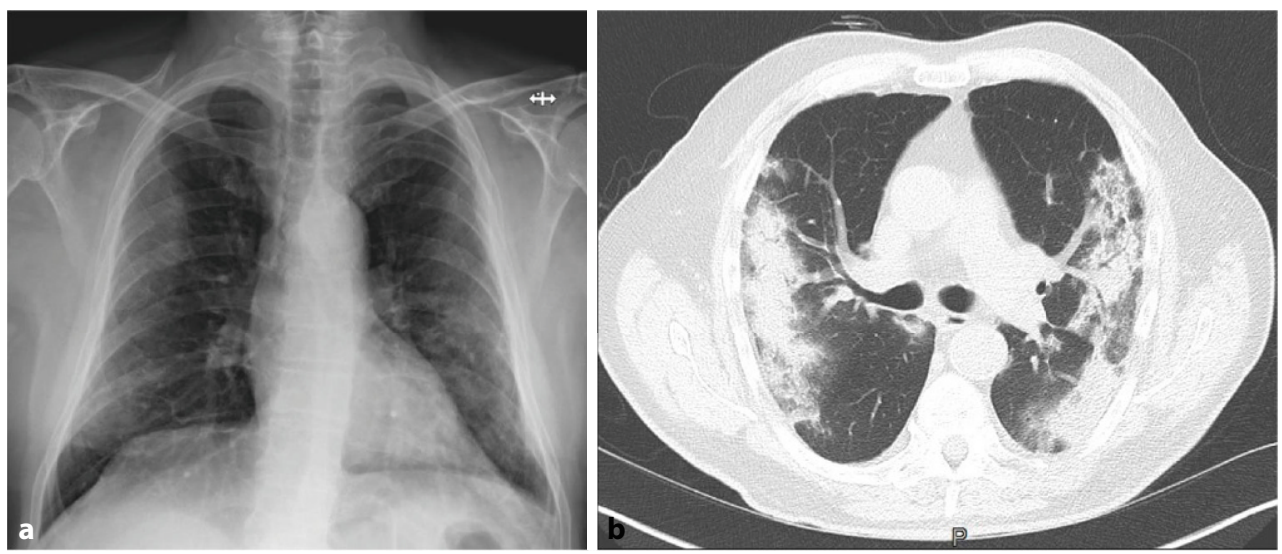

LUS revealed numerous small shred signs all over the lungs, without hepatization. Thus, viral pneumonia was indicated, and withdrawal of antibiotics recommended. The latter, however, were still continued. Tests for SARS-CoV-2 were negative. A chest CT showed signs of bronchiolitis and pulmonary nodules suspicious for lung cancer. Due to (viral) infectious exacerbation of underlying COPD, the patients clinical condition worsened and he died 4 weeks after admission.

\section{Case 3: SARS-CoV-2}

In a 67 -year-old patient with fever, cough for about 2 weeks and a negative COVID-19-PCR, a chest film showed bilateral infiltrates (Fig. 1a). Ampicillin/ sulbactam was started.

LUS revealed small shred signs and focal B-lines all over the lung (Fig. 2a-c), consistent with viral pneumonia. Thus, antibiotic therapy was withdrawn and a CT scan for correlation was suggested; however, another chest film (not shown) was carried out instead, which showed the same infiltrates as before, and ampicillin/sulbactam was again prescribed. A CT scan 4 days later revealed signs suggestive for COVID19 (Fig. 1b). Antibodies against SARS-CoV-2 (Table 1) were detected and the patient was isolated. Despite falling CRP levels and the negative PCT, levofloxacin was added to ampicillin/sulbactam. Finally, the pa- tient's clinical condition improved and he could be transferred to the regular ward.

\section{Cases 2 and 3-Discussion}

Both cases, confirmed by negative PCT and suggestive radiologic findings, are examples of a viral respiratory infection that should be managed without antibiotics.

\section{Case 4: Bacterial superinfection of viral pneumonia complicating breast cancer}

A 74-year-old woman was started on piperacillin/ tazobactam because of chills, fever, and coughing with purulent bloody sputum. Furthermore, a retracted left mammilla was noted. A chest film showed patchy infiltrates and some pleural effusion (Fig. 3a). See Table 1 for laboratory results.

LUS revealed pleural irregularities in the right upper field, a small shred sign in the apical left upper field, and hepatization of the lung in the left middle and lower field, with a $2 \mathrm{~cm}$ pleural effusion on the left side (Fig. 4a-c); in addition, a node suspicious for breast cancer was detected.

CRP fell slowly and the patient met the criteria for stability (see supplementary material). Therefore, therapy was de-escalated to penicillin p.o. after day three of treatment. Therapy was switched back to piperacillin/tazobactam 2 days later without new symptoms, due to concerns by another physician
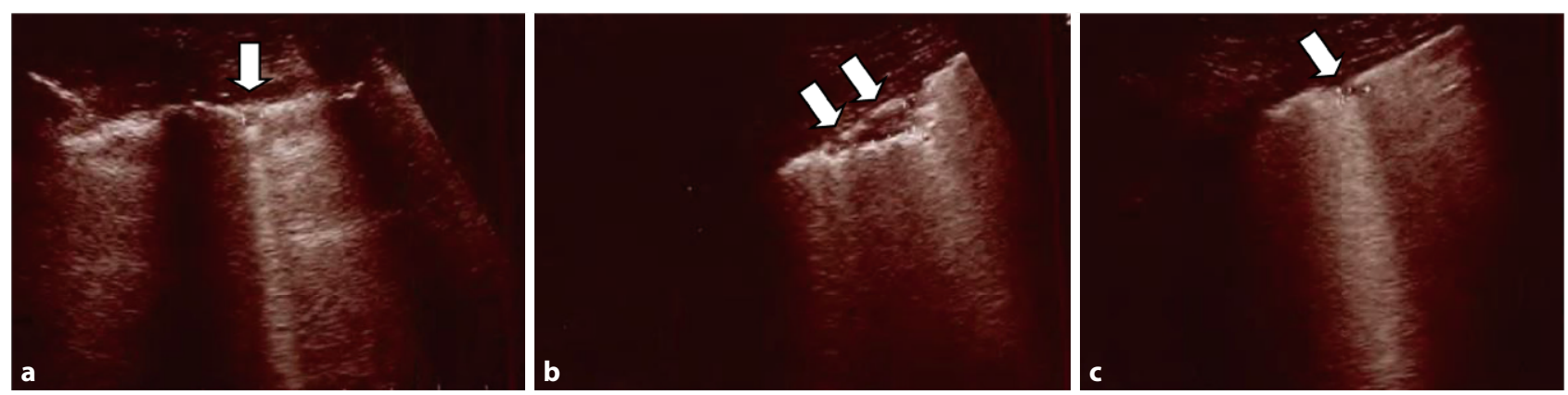

Fig. 2 Case 3: Lung sonography shows a a small shred sign with B-line in the right upper lobe (white arrow); $\mathbf{b}$ another shred sign (white arrows) with several B-lines; and c a small shred sign with a broad B-line (waterfall sign) in the right lower lobe 

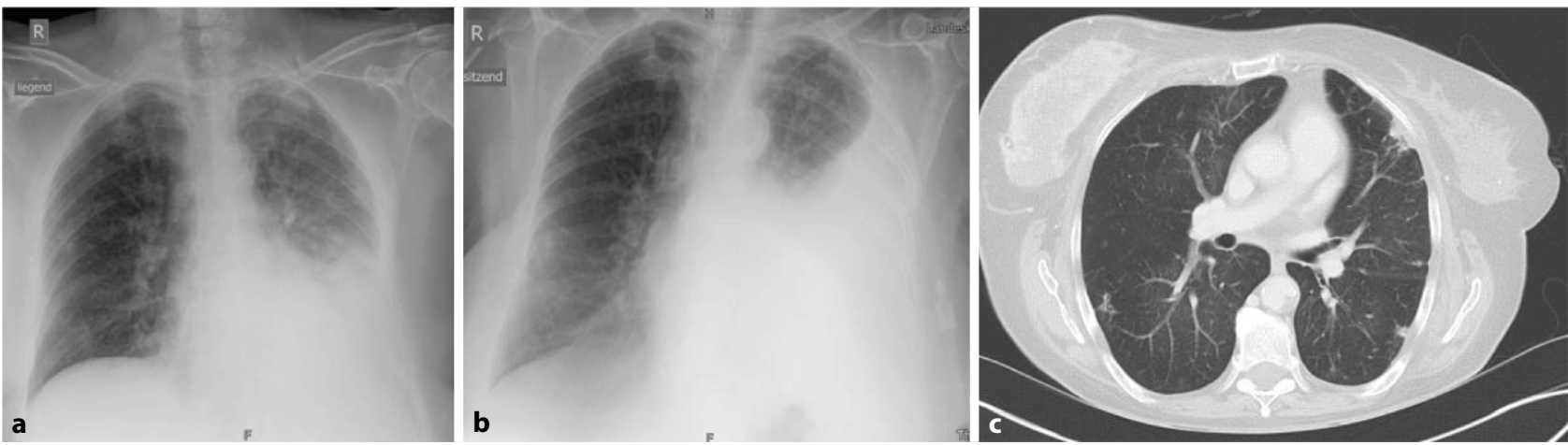

Fig. 3 Case 4: a Infiltrative changes in the left lower lung, atelectasis, and some pleural effusion on the left side. Patchy changes in the upper left lung. Alveolar infiltrates in the right lung; b extensive left-sided pleural effusion; c CT shows numerous subpleural consolidation areas and signs of bronchiolitis. Furthermore, a right-sided breast tumor was detected
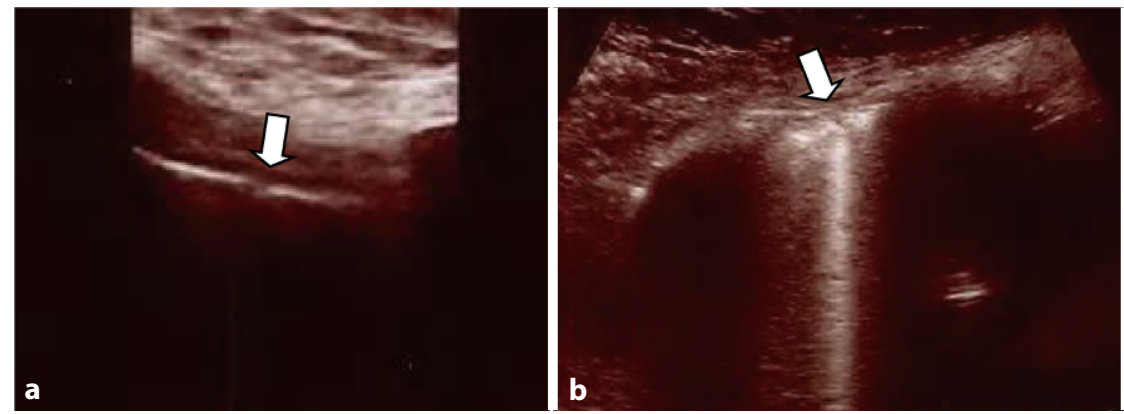

Fig. 4 Case 4: a Lung sonography of the right upper lobe shows a pleural irregularity (white arrow); b lung sonography of the left upper lobe shows a small shred sign (white arrow)

regarding the initially high CRP level. Finally, the patient was transferred to a physiotherapy department with oral amoxicillin/clavulanic acid. There, she suffered from respiratory distress and weakness. Rising CRP and lymphopenia were noticed and a chest film revealed an increasing pleural effusion (Fig. 3b). The effusion was withdrawn by puncture and pleural empyema was ruled out by chemical analysis. She was readmitted and the therapy was switched to cefuroxime.

LUS again revealed shred signs, and the hepatization showed regression. Serologic studies of antibodies against several viral agents were carried out twice; enterovirus tested positive for IgM and negative for IgG.

A chest CT (Fig. 3c) showed signs of breast cancer, enlarged lymph nodes in the right axilla, and a consolidation in the left lower lung; moreover, numerous small consolidation areas and signs of bronchiolitis were detected, consistent with viral pneumonia with bacterial superinfection. The patient was discharged 1 week later.

\section{Case 4-Discussion}

Streptococcal superinfection of underlying enterovirus pneumonia represents two of the most common respiratory pathogens [48]. Antibiotic de-escalation is with a B-wave; c lung sonography of the left lower lobe shows hepatization of the lung tissue (white arrows)

recommended in pneumococcal pneumonia [49]; however, a senior doctor not familiar with this practice revoked this step. Neither fever nor cough was noticed, pleural empyema was ruled out, and no rise of PCT or left shift was documented. Thus, the effusion could reflect an immunologic reaction, or cardiac decompensation rather than a flare-up of the bacterial infection. Moreover, viral infection itself has been shown to cause a parapneumonic effusion [50].

\section{Case 5: Norovirus and viral pneumonia in an immunocompromised patient}

A 56-year-old woman with a history of Crohn's disease and common variable immune deficiency (CVID) presented with fever, dry cough, weakness, sweats, loose stools, and dysuria, of a few days duration. Tests for SARS-CoV-2 were negative (see Table 1 for laboratory results). A chest film showed infiltrates in the right lower lobe. Pneumococcal urinary antigen was positive and ampicillin/sulbactam was started. Thereafter, she suffered from profuse watery stools; thus, antibiotic therapy was withdrawn.

LUS indicated signs of viral pneumonia. In addition, stool tests were positive for norovirus-confirmed gastroenteritis. She recovered with supportive therapy and was discharged. 


\section{Case 5-Discussion}

Pneumococcal antigens can represent colonization without infection [51] and chest films may not reliably distinguish between viral and bacterial pneumonia [16]. LUS indicated viral pneumonia in the context of viral gastroenteritis. The patient herself wished to withdraw antibiotic therapy after 2 days, which was the correct decision from an antibiotic stewardship perspective.

The spectrum of norovirus disease in immunocompromised patients is not well defined. Extraintestinal spread and replication, including viremia, as well as infection by inhalation of aerosolized vomitus particles, have been described [52]. Moreover, norovirus has been recovered from nasopharyngeal swabs [53]. Therefore, the consolidation may represent either an extraintestinal manifestation of norovirus disease or another undetected pathogen.; however, bacterial pneumonia was excluded given the recovery with insufficient antibiotic therapy in an immunocompromised patient.

\section{Discussion}

\section{Main discussion and review of literature}

Delayed treatment of bacterial pneumonia results in high mortality and morbidity; however, viral respiratory infections, including pneumonia, are increasingly recognized, and clinical investigation or x-ray to distinguish them from bacterial pneumonia seems to be inappropriate [16].

Antibiotics, the "drugs of fear," are overused in a "better safe than sorry" approach [1], which contributes to antimicrobial resistance [1-15]. This is all the more relevant in respiratory infections, since viral infections seem to enhance the dynamics of antibiotic-resistant gene expression in bacteria located in the airways [54] in which the colonic resistance is disturbed by antibiotics [55]. The disturbance of the human microbiome has been shown to increase viral titers in the case of influenza and decrease survival in mice infected with Streptococcus- if they were pretreated with antibiotics [31].

Furthermore, undetected viral infection and thus, the failure to isolate patients, can lead to outbreaks in healthcare systems with significant morbidity, mortality, and costs [17-30]. This is also true for the ongoing COVID-19 pandemic [56].

The understanding of pneumonia has changed from a picture of sterile lungs attacked by pathogens, to a complex microbial ecosystem [55], where outgrowth of a bacterial pathogen is the result of a disturbing event of homeostasis and not the cause [55, 57, 58]. Viral infection represents such an event; however, antibiotics should be avoided before a bacterial superinfection has been established.

Therefore, PCT levels were extensively studied as a biomarker in respiratory infections. PCT-guided therapy has been shown to spare antibiotics while decreasing mortality and morbidity [32, 33], reflecting the negative influence of antibiotics in pure viral disease. It is worth pointing out here that elevated $\mathrm{C}$-reactive protein levels have been reported in viral infections [59-62]; therefore, the value of these levels to corroborate bacterial superinfection is doubtful.

LUS can confirm a diagnosis of viral pneumonia in case of low PCT levels. Both LUS and PCT can repeatedly be used to detect bacterial superinfection over the course of the disease. Thus, antibiotics may be avoided in patients with results of chest films or CRP values indicative of bacterial infection. Clearly, further studies are needed to confirm this hypothesis, as our data consists of case descriptions.

Some viruses may have been neglected as a cause of severe airway diseases in the past $[48,63]$ and the recognition of severe viral pulmonary disease without bacterial superinfection is increasing $[16,27,48$, $59,63]$. While the significance of respiratory viruses in patients without typical respiratory infection is under discussion [64], pulmonary disease in the course of viral gastroenteritis has been rarely documented [46] and nasopharyngeal detection of gastroenteritis viruses is of unknown significance [53]. Here, LUS raises the possibility of documented lung involvement in case of a viral infection, such as in cases 1 and 5 (astrovirus and norovirus, respectively).

\section{Conclusion}

Antimicrobial stewardship is crucial to preserve the efficacy of existing antibiotics in patients with antimicrobial-resistant micro-organisms. In unclear cases of lung infection, LUS, in combination with PCT, seems to be a more accurate method with which to discriminate between viral and bacterial pneumonia. Avoidance of unnecessary antibiotic therapy in viral infection may improve the outcome of the individual patient. This will also contribute to lowering the rate of antimicrobial-resistance. Furthermore, insights into the spectrum of viral disease, with regard to lung involvement in the case of certain viruses, may be gained as well.

Acknowledgements All laboratory results were provided by the Institute of laboratory medicine clinical chemistry and molecular diagnostics, Prim. Dr. Karin Köhrer, MSc, MBA.

Author Contribution L. Antonitsch wrote the manuscript with advice and contributions by G. Weidinger, R. Gallob and J. Kettenbach and revision by J. Kettenbach. All authors contributed to the manuscript. Finally, all authors have read and approved the manuscript. See supplementary material for further information.

\section{Declarations}

Conflict of interest L. Antonitsch, R. Gallob, G. Weidinger and J. Kettenbach declare that they have no competing interests. 
Ethical standards No ethics committee was involved since this is a case series. All patients gave written consent for publication of data and images (see below), also in case of patient 2 (case 2). Written informed consent for publication of their clinical details and/or clinical images was obtained from the patients; copies of the signed, written informed consent for publication forms are available for review by the editors. The patient of case 2 gave written informed consent to LA on occasion of the lung ultrasound examination. He died weeks later on a different ward.

\section{References}

1. Kunin CM, Tupasi T, Craig WA. Use of antibiotics: a brief exposition of the problem and some tentative solutions. Ann Intern Med. 1973;79(4):555-60.

2. Price DJE, Sleigh JD. Control of infection due to Klebsiella aerogenes in a neurosurgical unit by withdrawal of all antibiotics. Lancet. 1970;296(7685):1213-5.

3. Selden R, et al. Nosocomial Klebsiella infections: intestinal colonization as a reservoir. Ann Intern Med. 1971;74(5):657-64.

4. Woerther P-L, Andremont A, Kantele A. Travel-acquired ESBL-producing Enterobacteriaceae: impact of colonization at individual and community level. J Travel Med. 2017;24(suppl_1):S29-S34.

5. KanteleA, etal. Antimicrobialsincrease travelers' risk of colonization by extended-spectrum betalactamase-producing Enterobacteriaceae. Clin Infect Dis. 2015;60(6):837-46.

6. Cassini A, et al. Attributable deaths and disability-adjusted life-years caused by infections with antibiotic-resistant bacteriain theEU and theEuropean Economic Areain 2015: a population-level modelling analysis. Lancet Infect Dis. 2019;19(1):56-66.

7. Jarlier V, et al. Strong correlation between the rates of intrinsically antibiotic-resistant species and the rates of acquired resistance in Gram-negative species causing bacteraemia, EU/EEA, 2016. Euro Surveill. 2019;24(33):1800538. https:/ / doi.org/10.2807/1560-7917.ES.2019.24.33.1800538

8. European Centre for Disease Prevention and Control. Proposals for EU guidelines on the prudent use of antimicrobials in humans. Stockholm: ECDC; 2017.

9. Kärki T, et al. Burden of healthcare-associated infections in European acute care hospitals. Wien Medizinische Wochenschrift. 2019;169(1):3-5.

10. Friedrich AW. Control of hospital acquired infections and antimicrobial resistance in Europe: the way to go. Wien Med Wochenschr. 2019;169(1):25-30.

11. Wang Q, et al. Risk factors and clinical outcomes for carbapenem-resistant Enterobacteriaceae nosocomial infections. Eur JClin Microbiol Infect Dis. 2016;35(10):1679-89.

12. Hui C, et al. Previous antibiotic exposure and evolution of antibiotic resistance in mechanically ventilated patients with nosocomial infections. JCrit Care. 2013;28(5):728-34.

13. Wu D, Jiachang C, Liu J. Risk factors for the acquisition of nosocomial infection with carbapenem-resistant Klebsiella pneumoniae. South Med J.2011;104(2):106-10.

14. Superti Vargas S, Augusti G, Prehn Zavascki A. Risk factors for and mortality of extended-spectrum- $\beta$-lactamaseproducing Klebsiella pneumoniae and Escherichia coli nosocomial bloodstream infections. Rev Inst Med trop S Paulo. 2009;51(4):211-6.

15. Altunsoy A, et al. The impact of a nationwide antibiotic restriction program on antibiotic usage and resistance against nosocomial pathogens in Turkey. Int J Med Sci. 2011;8(4):339.
16. Chalmers JD. The modern diagnostic approach to community-acquired pneumonia in adults. Semin Respir Crit Care Med. 2016;37(6):876-885. https://doi.org/10.1055/s0036-1592125

17. Quirós-González V, et al. Real-time surveillance systems: applicability for the control of influenza in acute care. Influenza Other RespiViruses. 2020;14(3):331-339. https:// doi.org/10.1111/irv.12720

18. Sansone M, et al. Extensive hospital in-ward clustering revealed by molecular characterization of influenza A virus infection. Clin Infect Dis. 2020;71(9):e377-e383. https:// doi.org/10.1093/cid/ciaa108

19. Godoy P, et al. Hospital-acquired influenza infections detected by a surveillance system over six seasons, from 2010/2011 to 2015/2016. BMCInfect Dis. 2020;20(1):80.

20. Naudion P, Lepiller Q, Bouiller K. Risk factors and clinical characteristics of patients with nosocomial influenza A infection. J Med Virol. 2019;92(8):1047-1052. https://doi. org/10.1002/jmv.25652

21. Zhao X, et al. Airborne Transmission of Influenza Virus in a Hospital of Qinhuangdao During 2017-2018 Flu Season. Food Environ Virol. 2019;11(4):427-39.

22. Blackburn RM, et al. Nosocomial transmission of influenza: a retrospective cross-sectional study using next generation sequencing at a hospital in england (2012-2014). Influenza Other Respi Viruses. 2019;13(6):556-63.

23. Houlihan CF, et al. Use of whole-genome sequencing in the investigation of a nosocomial influenza virus outbreak. JINFECT DIS. 2018;218(9):1485-9.

24. Zhou F, et al. Risk factors for nosocomial infection among hospitalised severe influenza A (H1N1) pdm09 patients. Respir Med. 2018;134:86-91. https://doi.org/10.1016/j. rmed.2017.11.017

25. Heyd R, et al. Retrospective analysis of clinical and virological parameters of influenza cases at four university hospitals in Germany, 2015. Infection. 2017;45(3):349-54.

26. Álvarez-Lerma F, et al. Characteristics of patients with hospital-acquired influenza A (H1N1) pdm09 virus admitted to the intensive care unit. JHosp Infect. 2017;95(2):200-6.

27. Manchal N, et al. Hospital acquired viral respiratory tractinfections: an underrecognized nosocomial infection. Infect Dis Health. 2020;25(3):175-180. https://doi.org/10. 1016/j.idh.2020.02.002

28. Kakiuchi S, et al. Human parainfluenza virus type 3 infections in patients with hematopoietic stem cell transplants: the mode of nosocomial infections and prognosis. Jpn J Infect Dis. 2018;71(2):109-115. https://doi.org/10.7883/ yoken.JJID.2017.424

29. Loubet $\mathrm{P}$, et al. Impact of respiratory viruses in hospitalacquired pneumonia in the intensive care unit: a singlecenter retrospective study. JClin Virol. 2017;91:52-7.

30. Cui X, et al. Human adenovirus type 7 infection associated with severe and fatal acute lower respiratory illness and nosocomial transmission. J Clin Microbiol. 2015;53(2):746-9.

31. Hanada S, et al. Respiratory viral infection-induced Microbiome alterations and secondary bacterial pneumonia. Front Immunol. 2018;9:2640. https://doi.org/10.3389/ fimmu.2018.02640

32. Schuetz P, et al. Procalcitonin to initiate or discontinue antibiotics in acute respiratory tract infections. Evid Based Child Health. 2013;8(4):1297-371.

33. Schuetz P, et al. Effect of procalcitonin-guided antibiotic treatment on mortality in acute respiratory infections: a patient level meta-analysis. Lancet Infect Dis. 2018;18(1):95-107. 
34. Lippi G, Plebani M. Procalcitonin in patients with severe coronavirus disease 2019 (COVID-19): a meta-analysis. Clin Chim Acta. 2020;505:190-191. https://doi.org/10. 1016/j.cca.2020.03.004

35. Schuetz P, et al. Procalcitonin (PCT)-guided antibiotic stewardship: an international experts consensus on optimized clinical use. Clin Chem Lab Med (cclm). 2019;57(9):1308-18.

36. LeeC-C, etal. Combining procalcitonin and rapidmultiplex respiratory virus testing for antibiotic stewardship in older adult patients with severe acute respiratory infection. JAm MedDir Assoc. 2020;21(1):62-7.

37. Moradi T, et al. Use of procalcitonin and a respiratory polymerase chain reaction panel to reduce antibiotic use via an electronic medical record alert. Clin Infect Dis. 2019;71(7):1684-1689. https://doi.org/10.1093/cid/ ciz1042

38. Creamer AW, Alice EK, Albur M. Procalcitonin in respiratory disease: use as a biomarker for diagnosis and guiding antibiotic therapy. Breathe. 2019;15(4):296-304.

39. Lichtenstein DA, Meziere GA. Relevance of lung ultrasound in the diagnosis of acute respiratory failure*: the BLUE protocol. Chest. 2008;134(1):117-25.

40. Tsung JW, Kessler DO, Shah VP. Prospective application of clinician-performed lung ultrasonography during the 2009 H1N1 influenza A pandemic: distinguishing viral from bacterial pneumonia. Crit Ultrasound J.2012;4(1):1-10.

41. Berce V, et al. The usefulness of lung ultrasound for the aetiological diagnosis of community-acquired pneumonia in children. Sci Rep. 2019;9(1):1-10.

42. ArbelotC, etal. Lungultrasound in emergency and critically ill patientsnumber of supervised exams to reach basic competence. Anesthesiology. 2020;132(4):899-907.

43. Buonsenso D, et al. Point-of-care lung ultrasound findings in novel coronavirus disease-19 pnemoniae: a case report and potential applications during COVID-19 outbreak. Eur RevMed PharmacolSci. 2020;24:2776-80.

44. Moro F, et al. How to perform lung ultrasound in pregnant women with suspected COVID-19 infection. Ultrasound Obstet Gynecol. 2020;55(5):593-598. https://doi.org/10. 1002/uog.22028

45. Zhang H-W, et al. Corona virus international public health emergencies: implications for radiology management. Acad Radiol. 2020;27(4):463-467. https://doi.org/10.1016/ j.acra.2020.02.003

46. Bosch ARMP, Guix S. Human astroviruses. Clin Microbiol Rev. 2014;27(4):1048-74.

47. JegerV, etal. Is therearoleforprocalcitonin in differentiating uncomplicated and complicated diverticulitis in order to reduce antibiotic therapy? A prospective diagnostic cohort study. Swiss Med Wkly. 2017;147:w14555.

48. Musher DM, Abers MS, Bartlett JG. Evolving understanding of the causes of pneumonia in adults, with special attention to the role of pneumococcus. Clin Infect Dis. 2017;65(10):1736-44.
49. Viasus D, et al. Impact of antibiotic de-escalation on clinical outcomes in community-acquired pneumococcal pneumonia. JAntimicrob Chemother. 2017;72(2):547-53.

50. Nascimento-Carvalho CM, etal. Respiratoryviralinfections among children with community-acquired pneumoniaand pleural effusion. Scand J Infect Dis. 2013;45(6):478-83.

51. Hyams CO, Williams M, Williams P. Urinary antigen testing for pneumococcal pneumonia: is there evidence to make its use uncommon in clinical practice? ERJ Open Res. 2020;6(1):00223-2019. https://doi.org/10.1183/23120541. 00223-2019

52. Karst SM, Zhu S, Goodfellow IG. The molecular pathology of noroviruses. J Pathol. 2015;235(2):206-16.

53. Kweon OJ, et al. Fecal respiratory viruses in acute viral respiratory infection and nasopharyngeal diarrheal viruses in acute viral gastroenteritis: clinical impact of ectopic viruses is questionable. J Microbiol Biotechnol. 2018;28(3):465-72.

54. Zhang L, et al. Characterization of antibiotic resistance and host-microbiome interactions in the human upper respiratory tract during influenza infection. Microbiome. 2020;8(1):1-12.

55. de Steenhuijsen Piters WAA, Sanders EAM, Bogaert D. The role of the local microbial ecosystem in respiratory health and disease. Philos Trans R Soc Lond B Biol Sci. 2015;370(1675):20140294.

56. Bearden DM, et al. COVID-19: a primer for healthcare providers. Wien Klin Wochenschr. 2020;132(1314):390-395. https://doi.org/10.1007/s00508-020-01678$\mathrm{X}$

57. Dickson RP, Erb-Downward JR, Huffnagle GB. Homeostasis and its disruption in thelung microbiome. Am J Physiol Cell Mol Physiol. 2015;309(10):L1047-L55.

58. Quinton LJ, Walkey AJ, Mizgerd JP. Integrative physiology of pneumonia. Physiol Rev. 2018;98(3):1417-64.

59. Marcos MA, et al. The role of viruses in the aetiology of community-acquired pneumonia in adults. Antivir Ther. 2006;11(3):351.

60. Torres A, Loeches IM, Sligl W, Lee N. Severeflu management: a point of view. Intensive Care Med. 2020;46(2):153-162. https://doi.org/10.1007/s00134-019-05868-8

61. Guan W-j, et al. Clinical characteristics of coronavirus disease 2019 in China. N Engl J Med. 2020;382(18):1708-1720. https://doi.org/10.1056/NEJMoa2002032

62. Galli C, Plebani M. Clinical laboratory and SARS-CoV-2 infection: where do we stand? Clin Chem Lab Med. 2020;58(7):1139-1141. https://doi.org/10.1515/cclm2020-0372

63. To KKW, Yip CCY, Yuen K-Y. Rhinovirus-from bench to bedside. JFormos Med Assoc. 2017;116(7):496-504.

64. To KKW, et al. Respiratory virus infection among hospitalized adult patients with or without clinically apparent respiratory infection: a prospective cohort study. Clin Microbiol Infect. 2019;25(12):1539-45.

Publisher's Note Springer Nature remains neutral with regard to jurisdictional claims in published maps and institutional affiliations. 